\title{
OPTIMAL PAIRINGS SELECTION FROM FLIGHT SCHEDULE USING GENETIC ALGORITHM AND PARTICLE SWARM OPTIMIZATION WITH PENALTY
}

\author{
Mohamad Yusak Anshori ${ }^{1}$, Teguh Herlambang ${ }^{2}$, Dinita Rahmalia ${ }^{3}$ \\ and Abdul Muhith ${ }^{4}$ \\ ${ }^{1}$ Management Department - University of Nahdlatul Ulama Surabaya (UNUSA) \\ ${ }^{2}$ Information System Department, University of Nahdlatul Ulama Surabaya \\ ${ }^{3}$ Mathematics Department, University of Islam Darul Ulum Lamongan \\ ${ }^{4}$ Nursing Department, University of Nahdlatul Ulama Surabaya (UNUSA)
}

Abstract - Indonesia is a large archipelago country with large population so that the demands of flight service are very high. Because the demands of flight service, flight industry should minimize operational cost such as crew cost. Crew cost depends on pairings from flight schedule. Optimization model of this problem is selecting optimal pairings covering all flight numbers. In this research, optimal pairings selection will be applied by heuristic method like Genetic Algorithm (GA) and Particle Swarm Optimization (PSO) with penalty. GA uses natural selection process mechanism in chromosomes while PSO is optimization method inspired from the flock of fish or bird in searching food source. Both GA and PSO can be applied on constrained optimization. In order that satisfying constraints, chromosome in GA or particle in PSO will be given penalty if the constraint isn't satisfied. Simulations are applied by generating the set of pairings and selection using GA and PSO with penalty. Simulation result shows GA and PSO method with penalty can select optimal pairings in approaching.

Keywords - Flight schedule, Pairings selection, Genetic Algorithm, Particle Swarm Optimization, penalty

\section{INTRODUCTION}

Indonesia is a large archipelago country with large population so that the demands of flight service are very high. Because the demands of flight service, flight industry should minimize operational cost. There are two highest costs in flight industry. The highest cost is fuel cost and the second is crew cost. Crew cost depends on pairings from flight schedule. Pairing is the sequence of flights driven by a set of crews started from the airport in first flight until to the same airport in last flight. Each pairing is driven by a set of crews. Therefore the crews depart and arrive in the same airport (homebase) in their duty. Optimization model of this problem is selecting optimal pairings covering all flight numbers.

Optimal pairings selection is one of linear integer programming with constraints [3]. The constraints used are all flight numbers should be covered by one pairing. Because the decision variable is binary such as pairing is selected or not selected, then it is called

Received: September 26, 2019

Reviewed: December 6, 2019

Accepted: January 5, 2020

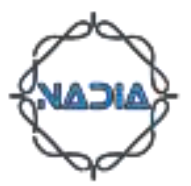


binary programming. Linear integer programming can be solved by exact method like simplex method, branch and bound method, and cutting plane method [5],[13]. Other method used in optimal pairings selection is greedy algorithm. In this research, optimal pairings selection will be applied by heuristic method like Particle Swarm Optimization (PSO) with penalty. PSO has been applied in many optimization problems such as transportation problem [8], control system [4], and forecasting data [9],

Genetic Algorithm (GA) was discovered by Goldberg at 1989. How GA works is using natural selection process mechanism in chromosomes. Some process of GA are initialization chromosome population, selection, crossover and mutation chromosome [2], [11]. Particle Swarm Optimization (PSO) was discovered by Kennedy and Eberhart in 1995. PSO is inspired by the behavior of flocks of birds, swarm of insects, or school of fish in which individuals are called particles and the population is called a swarm. The PSO is initialized with a group of random candidate solutions as a swarm of particles. Each particle is given initial position and velocity. When particle finds a direction to the source of food, other particles will follow them [6].

Both GA and PSO can be applied on constrained optimization. In order that satisfying constraints, chromosomes in GA or particle in PSO will be given penalty if the constraint isn't satisfied [7]. GA and PSO are optimization, but development of Kalman Filter for estimation $[14,15,16,17]$, and combination with GA.

Simulations are applied by generating the set of possible pairings. After the set of possible pairings are generated, then we select the set of selected pairings using GA and PSO with penalty if the flight number is covered more than one pairing. Simulation result shows GA and PSO method with penalty can select optimal pairings in approaching.

\section{LITERATURE REVIEW}

Pairing is the sequence of flights driven by a set of crews started from the airport in first flight until to the same airport in last flight. Each pairing is driven by a set of crews. Therefore the crews depart and arrive in the same airport (homebase) in their duty.

The method for constructing pairing is using possibility matrix $A^{n}, n=2,3,4,5,6$. Possibility matrix $A^{n}$ keeps pairing consisting of $n$ flight numbers so that each column of possibility matrix $A^{n}$ has $n$ elements with score equals 1 . Pairing illustrations can be seen on Figure 1, Figure 2, Figure 3, Figure 4, and Figure 5. Pairing $A^{n}$ consists of $n$ flight numbers [10].

\begin{tabular}{|c|c|c|c|c|}
\hline $\begin{array}{c}\text { Pte } \\
\text { Journey } \\
(90 \mathrm{mnt})\end{array}$ & $\begin{array}{c}\text { Fight 1 } \\
(\mathrm{A} \rightarrow \mathrm{B})\end{array}$ & $\begin{array}{c}\text { Transit } \\
\text { Time } \\
(T T)\end{array}$ & $\begin{array}{c}\text { Flight } 2 \\
(B \rightarrow A)\end{array}$ & $\begin{array}{c}\text { Post } \\
\text { Journey } \\
(90 \mathrm{mnt})\end{array}$ \\
\hline
\end{tabular}

Fig. 1 Pairing $A^{2}$ consisting of 2 flight numbers

\begin{tabular}{|c|c|c|c|c|c|c|}
\hline $\begin{array}{c}\text { Pre } \\
\text { journey } \\
(90 \mathrm{mnt})\end{array}$ & $\begin{array}{c}\text { Flight 1 } \\
(\mathrm{A} \rightarrow \mathrm{B})\end{array}$ & $\begin{array}{c}\text { Transit } \\
\text { Time } \\
(\mathrm{T})\end{array}$ & $\begin{array}{c}\text { Fight 2 } \\
(B \rightarrow C)\end{array}$ & $\begin{array}{c}\text { Transit } \\
\text { Time } \\
(\mathrm{B})\end{array}$ & $\begin{array}{c}\text { Flight } 3 \\
(\mathrm{C} \rightarrow \mathrm{A})\end{array}$ & $\begin{array}{c}\text { Post } \\
\text { Journey } \\
(90 \mathrm{mnt})\end{array}$ \\
\hline
\end{tabular}

Fig. 2 Pairing $A^{3}$ consisting of 3 flight numbers

\begin{tabular}{|c|c|c|c|c|c|c|c|c|}
\hline $\begin{array}{c}\text { Pro } \\
\text { Joumey } \\
(90 \text { mnt })\end{array}$ & $\begin{array}{c}\text { Flight 1 } \\
(\mathrm{A} \rightarrow \mathrm{B})\end{array}$ & $\begin{array}{c}\text { Transit } \\
\text { Time } \\
(T)\end{array}$ & $\begin{array}{c}\text { Flight 2 } \\
(\mathrm{B} \rightarrow \mathrm{C})\end{array}$ & $\begin{array}{c}\text { Transit } \\
\text { Time } \\
(T)\end{array}$ & $\begin{array}{c}\text { Fleht 3 } \\
(\mathrm{C} \rightarrow \mathrm{D})\end{array}$ & $\begin{array}{c}\text { Transit } \\
\text { Time } \\
(\pi)\end{array}$ & $\begin{array}{c}\text { Flight 4 } \\
(\mathrm{D} \rightarrow \mathrm{A})\end{array}$ & $\begin{array}{c}\text { Post } \\
\text { Journey } \\
(90 \text { mnt })\end{array}$ \\
\hline
\end{tabular}

Fig. 3 Pairing $A^{4}$ consisting of 4 flight numbers 


\begin{tabular}{|c|c|c|c|c|c|c|c|c|c|c|}
\hline $\begin{array}{c}\text { Pre } \\
\text { journey } \\
\text { (90mnt) }\end{array}$ & $\begin{array}{l}\text { Flight } 1 \\
(A \rightarrow 8)\end{array}$ & $\begin{array}{l}\text { Transit } \\
\text { Time } \\
\text { (TI] }\end{array}$ & $\begin{array}{l}\text { Fight } 2 \\
(B \rightarrow C)\end{array}$ & $\begin{array}{l}\text { Transit } \\
\text { Time } \\
\text { (TT) }\end{array}$ & $\begin{array}{l}\text { Flight } 3 \\
(c \rightarrow D)\end{array}$ & $\begin{array}{l}\text { Transit } \\
\text { Time } \\
\text { (IT) }\end{array}$ & $\begin{array}{l}\text { Flight } 4 \\
(D \rightarrow \xi)\end{array}$ & $\begin{array}{l}\text { Transit } \\
\text { Time } \\
\text { (TT) }\end{array}$ & $\begin{array}{l}\text { Fight } 5 \\
(E \rightarrow A)\end{array}$ & $\begin{array}{c}\text { Post } \\
\text { Joumey } \\
\text { (90 mnt) }\end{array}$ \\
\hline
\end{tabular}

Fig. 4 Pairing $A^{5}$ consisting of 5 flight numbers

\begin{tabular}{|c|c|c|c|c|c|c|c|c|c|c|c|c|}
\hline $\begin{array}{c}\text { Pre } \\
\text { Journey } \\
\text { (90 mnt) }\end{array}$ & $\begin{array}{l}\text { Figint } 1 \\
(A \rightarrow B)\end{array}$ & $\begin{array}{c}\text { Transit } \\
\text { Time } \\
\text { (TT) }\end{array}$ & $\begin{array}{l}\text { Fight } 2 \\
\langle\mathrm{~B} \rightarrow \mathrm{C})\end{array}$ & $\begin{array}{l}\text { Trans? } \\
\text { Time } \\
\text { (III) }\end{array}$ & $\begin{array}{l}\text { Flght } 3 \\
(C \rightarrow D)\end{array}$ & $\begin{array}{l}\text { Trassit } \\
\text { Time } \\
\text { (IT) }\end{array}$ & $\begin{array}{l}\text { Flght } 4 \\
{[D \rightarrow E]}\end{array}$ & $\begin{array}{c}\text { Trassit } \\
\text { Time } \\
\text { (IT) }\end{array}$ & $\begin{array}{l}\text { Filght 5 } \\
(E \rightarrow F)\end{array}$ & $\begin{array}{c}\text { Transit } \\
\text { Time } \\
\text { (IT) }\end{array}$ & $\begin{array}{l}\text { Flight } 6 \\
(F \rightarrow A)\end{array}$ & $\begin{array}{c}\text { Post } \\
\text { Jaurney } \\
\text { (90 mnt) }\end{array}$ \\
\hline
\end{tabular}

Figure 5. Pairing $A^{6}$ consisting of 6 flight numbers

In the optimal pairing selection, there are some cases the flight numbers are deadhead on Figure 6. Deadhead is the case in which there are same flight numbers in the different pairing so that flight number is covered more than one pairing. This problem causes a set of crews is transfered to destination airport with other flight in different pairing.

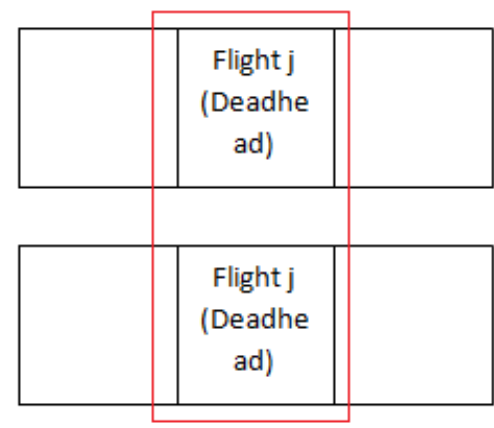

Pairing K1

Fig. 6 Deadhead Situation

\section{MATHEMATICAL MODEL OF SET COVERING PROBLEM}

Optimal pairings selection can be done by generating the set of possible pairing of each flight number. After the set of possible pairings are generated, they will be selected the set of selected pairings subject to all flight number are covered by one pairing. The model is called set covering problem.

Mathematical model of optimal pairings selection is as follows [10] :

$$
\min \sum_{k=1}^{N_{P}} c_{k} x_{k}+\sum_{i=1}^{N_{F}} d_{i}\left(\sum_{k=1}^{N_{P}} a_{i k} x_{k}-1\right)
$$

Subject to :

$$
\begin{gathered}
\sum_{k=1}^{N_{P}} a_{i k} x_{k}=1, \quad i=1,2, \ldots, N_{F} \\
x_{k} \in\{0,1\}, k=1,2, \ldots, N_{P}
\end{gathered}
$$

The objective function in equation (1) is : $\sum_{k=1}^{N_{P}} c_{k} x_{k}$ is objective function and $\sum_{i=1}^{N_{F}} d_{i}\left(\sum_{k=1}^{N_{P}} a_{i k} x_{k}-1\right)$ is penalty term [2]. Variables used are :

$N_{P}$ : The number of possible pairings

$N_{F}$ : Total flight numbers 
$c_{k}:$ Cost of pairing $k$

$d_{i}$ : Cost of deadhead with flight number $i$

with decision variables are :

$$
a_{i k}=\left\{\begin{array}{lr}
1, & \text { if flight number } \mathrm{i} \text { is covered in pairing } \mathrm{k} \\
0, & \text { otherwise }
\end{array}\right.
$$

$$
x_{k}= \begin{cases}1, & \text { if pairing } \mathrm{k} \text { is selected } \\ 0, & \text { otherwise }\end{cases}
$$

\section{INITIALIZATION THE PARTICLE}

Optimal pairings selection is applied by Genetic Algorithm (GA) and Particle Swarm Optimization (PSO). In the GA and PSO, we need to initialize population of the sets of selected pairings in equation (4) as particle by greedy algorithm. Greedy algorithm is applied because it can result binary solutions based on equation (3) and it can cover all flight numbers at least one pairing based on equation (2). There are cases where the particle position can not satisfy the constraint in equation (2) so that penalty value $\sum_{i=1}^{N_{F}} d_{i}\left(\sum_{k=1}^{N_{P}} a_{i k} x_{k}-1\right)$ to added in fitness function $\sum_{k=1}^{N_{P}} c_{k} x_{k}$. Because the solutions of this problem are binary then the mathematical model is binary programming. The algorithm to initialize population of the sets of selected pairings as decision variables is as follows :

For $j=1: \max$ pop

1. Suppose $U$ is the set of uncovered flight number, $S_{i}, i=1,2, \ldots, N_{F}$ is the pairing covering flight number $i, w_{i}, i=1,2, \ldots, N_{F}$ is the number of pairing covering flight number $i$, and $x_{k}=0, k=1,2, \ldots, N_{P}$ is the decision variable solution i.e. selected pairings.

2. Set $U=F, S_{i}=\{\}, w_{i}=0$ for every $i=1,2, \ldots, N_{F}, x_{k}=0$ for every $k=1,2, \ldots, N_{P}$

For $i=1: N_{F}$

If $\left(w_{i}=0\right)$
a. Determine $P_{i}$ : the set of pairings covering flight number $i$
b. Choose pairing $q \in P_{i}$ randomly
c. Determine $F_{q}$ : the set of flight numbers covered by pairing $q \in P_{i}$
d. Update $S_{i} \leftarrow S_{i} \cup q, w_{i} \leftarrow w_{i}+1$ for $i \in F_{q}$
e. Update $U \leftarrow U-F_{q}, x_{q}=1$

End

End

End 


\section{GENETIC ALGORITHM WITH PENALTY}

Genetic Algorithm (GA) was discovered by Goldberg at 1989. How GA works is using natural selection process mechanism in chromosomes. Some process of GA are initialization chromosome population, selection, crossover and mutation chromosome [2].

\section{POPULATION SELECTION}

In $\mathrm{GA}$, selection process is replacing some chromosomes with the others to create new population [2]. Selection process works like roulette wheel. Selection process can be explained as follows:

1. Calculate the fitness value $f\left(X^{j}\right), j=1,2, \ldots, \max$ pop

2. Calculate the total fitness for the population

$$
F=\sum_{j=1}^{\max p o p} f\left(X^{j}\right)
$$

3. Calculate the selection probability $p_{j}$

$$
p_{j}=\frac{f\left(X^{j}\right)}{F}, j=1,2, \ldots, \max \text { pop }
$$

4. Calculate cumulative probability $q_{j}$

$$
q_{j}=\sum_{i=1}^{j} p_{i}
$$

5. Generate a random number $r$ randomly between 0 and 1

6. If $r \leq q_{1}$, select first chromosome $X^{1}$, otherwise, select the k-th chromosome $X^{j}$ such that $q_{j-1}<r \leq q_{j}$

\section{CROSSOVER CHROMOSOMES}

In GA, crossover process is exchanging the element position of two parent chromosomes to become new chromosomes based on crossover probability $p_{c}$ [2]. Crossover operator can improve optimal solution resulted by GA because crossover operator can explore the new solution. Crossover operator must be designed to satisfy constraints in equation (2) and equation (3). There are cases where the chromosomes can not satisfy the constraint in equation (2) so that penalty value $\sum_{i=1}^{N_{F}} d_{i}\left(\sum_{k=1}^{N_{P}} a_{i k} x_{k}-1\right)$ to added in fitness function $\sum_{k=1}^{N_{P}} c_{k} x_{k}$. The algorithm of crossover operator is :

1. Select two chromosomes randomly $x_{k}^{j 1}, k=1,2, \ldots, N_{P}$ as first parent and $x_{k}^{j 2}$, $k=1,2, \ldots, N_{P}$ as second parent

2. Determine the element position of two parents $1 \leq k \leq N_{P}$ which have value $x_{k}=1$

3. Exchange the element position of two parents so that result new $x_{k}^{j 1}$ and $x_{k}^{j 2}$

For $k=1,2, \ldots, N_{P}$

If $\left(x_{k}^{j 1}=1\right.$ XOR $\left.x_{k}^{j 2}=1\right)$

$$
\begin{aligned}
& \text { temp }=x_{k}^{j 2} \\
& x_{k}^{j 2}=x_{k}^{j 1}
\end{aligned}
$$




$$
\begin{aligned}
& x_{k}^{j 1}=\text { temp } \\
& \text { end } \\
& \text { end }
\end{aligned}
$$

4. Do the following procedure so that all flight numbers are covered at least one pairing.

For $i=1: N_{F}$

$$
\text { If }\left(w_{i}=0\right)
$$
a. Determine $P_{i}$ : the set of pairings covering flight number $i$.
b. Choose pairing $q \in P_{i}$ randomly
c. Determine $F_{q}$ : the set of flight numbers covered by pairing $q \in P_{i}$
d. Update $S_{i} \leftarrow S_{i} \cup q, w_{i} \leftarrow w_{i}+1$ for $i \in F_{q}$
e. Update $U \leftarrow U-F_{q}, x_{q}=1$

\section{End}

End

\section{MUTATION CHROMOSOMES}

In GA, mutation process is changing some element of origin chromosome to become new chromosome based on mutation probability $p_{m}$ [2]. Mutation operator can improve optimal solution resulted by GA because mutation operator can explore the new solution. Mutation operator must be designed to satisfy constraints in equation (2) and equation (3). There are cases where the chromosomes can not satisfy the constraint in equation (2) so that penalty value $\sum_{i=1}^{N_{F}} d_{i}\left(\sum_{k=1}^{N_{P}} a_{i k} x_{k}-1\right)$ to added in fitness function $\sum_{k=1}^{N_{P}} c_{k} x_{k}$.The algorithm of mutation operator is :

1. Select $x_{k}^{j}, k=1,2, \ldots, N_{P}$

2. Determine the number of changed elements $1 \leq k \leq N_{P}$ which have value $x_{k}=1$

3. Change with new elements with value 0 or 1 so that result new $x_{k}^{j}$

4. Do the following procedure so that all flight numbers are covered at least one pairing.

For $i=1: N_{F}$

$$
\text { If }\left(w_{i}=0\right)
$$

a. Determine $P_{i}$ : the set of pairings covering flight number $i$.

b. Choose pairing $q \in P_{i}$ randomly

c. Determine $F_{q}$ : the set of flight numbers covered by pairing $q \in P_{i}$

d. Update $S_{i} \leftarrow S_{i} \cup q, w_{i} \leftarrow w_{i}+1$ for $i \in F_{q}$ 
e. Update $U \leftarrow U-F_{q}, x_{q}=1$

End

End

\section{PARTICLE SWARM OPTIMIZATION WITH PENALTY}

PSO is an optimization method discovered by Kennedy and Eberhart in1995. PSO is inspired by the behavior of flocks of birds, swarm of insects, or school of fish in which individuals are called particles and the population is called a swarm. The PSO is initialized with a group of random candidate solutions as a swarm of particles. When particle finds a direction to the source of food, other particles will follow them.

The basic PSO algorithm is as follows [12]:

1. Generate initialization particle position $x_{k}{ }^{j}(0), j=1,2, \ldots, \max$ pop

2. Generate initialization particle velocity $v_{k}{ }^{j}(0), j=1,2, \ldots, \max$ pop

3. Set local best particle $p_{k}{ }^{j}=x_{k}{ }^{j}(0), j=1,2, \ldots, \max$ pop

4. Set global best particle $g_{k}=\arg \min \left(f\left(p_{k}{ }^{j}\right), j=1,2, .\right.$. maxpop $)$

5. Update particle along time $t$.

for $t=0:$ max $\_t$

for $k=1,2, \ldots, \max$ pop

- Calculate the transformed particle velocity $v_{k}{ }^{j}(t+1)$

$$
v_{k}^{j}(t+1)=\omega v_{k}^{j}(t)+c_{1} r_{1}\left(p_{\text {best }}^{j}-x_{k}^{j}(t)\right)+c_{2} r_{2}\left(g_{\text {best }}-x_{k}^{j}(t)\right)
$$

With the value of $\omega$ is the inertia between 0.9-1.2, $c_{1}=c_{2}=2, r_{1}$ and $r_{2}$ are random number between $(0,1)$.

- Update the particle position $x_{k}{ }^{j}(t+1)$

$$
x_{k}^{j}(t+1)=x_{k}^{j}(t)+v_{k}^{j}(t+1)
$$

- Calculate the fitness of particle $f\left(x_{k}{ }^{j}(t+1)\right)$ with penalty

- Update local best particle $p_{k}{ }^{j}$

$$
{p_{k}}^{j}=\arg \min \left(f\left(x_{k}{ }^{j}(0)\right), f\left(x_{k}^{j}(1)\right), \ldots, f\left(x_{k}^{j}(t)\right), f\left(x_{k}{ }^{j}(t+1)\right)\right.
$$

end

Update global best particle $g_{k}$

$$
g_{k}=\underset{p}{\arg \min }\left(f\left(p_{k}{ }^{j}\right), j=1,2, \ldots \max \text { pop }\right)
$$

end

\section{UPDATE THE PARTICLE}

We need to modify the particle position and velocity update on PSO so that new particle can satisfy constraints in equation (2) and equation (3). The modification of particle position and velocity update can be designed as follows [1] : 
1. Compute the velocity update equation

$$
v_{k}^{j}(t+1)=\omega v_{k}^{j}(t)+c_{1} r_{1}\left(p_{\text {best }}^{j}-x_{k}^{j}(t)\right)+c_{2} r_{2}\left(g_{\text {best }}-x_{k}^{j}(t)\right)
$$

With the value of $\omega$ is the inertia between 0.9-1.2, $c_{1}=c_{2}=2, r_{1}$ and $r_{2}$ are random number between $(0,1)$.

2. Compute the particle position update equation. The modifications are required so that the particle position may satisfy the constraints. There are cases where the particle position can not satisfy the constraint in equation (2) so that penalty value $\sum_{i=1}^{N_{F}} d_{i}\left(\sum_{k=1}^{N_{P}} a_{i k} x_{k}-1\right)$ to added in fitness function $\sum_{k=1}^{N_{P}} c_{k} x_{k}$.

a. Choose random number $z \sim U(0.6 ; 1)$ between 0,6 until 1 uniformly distributed

b. Transform velocity update equation to sigmoid function valued between 0 until 1.

$$
\operatorname{sigm}\left(v_{k}^{j}\right)=\frac{1}{1+\exp \left(-\lambda v_{k}^{j}\right)}
$$

with steepness $\lambda=1$

c. Calculate particle position $x_{k}^{j}(t+1)$ based on equation (14)

$$
x_{k}^{j}(t+1)=\left\{\begin{array}{lr}
1, & \text { if } \mathrm{z}<\operatorname{sigm}\left(\mathrm{v}_{\mathrm{k}}^{\mathrm{j}}(\mathrm{t}+1)\right) \\
0, & \text { otherwise }
\end{array}\right.
$$

d. If $x_{k}^{j}(t+1)=1$, then determine $F_{k}$ i.e. flight number covered by pairing $k$.

e. Update $U=U-F_{k}, S_{i}=S_{i} \cup F_{k}, w_{i}=w_{i}+1$ for $i \in F_{k}$

f. Do the following procedure so that all flight numbers are covered at least one pairing.

For $i=1: N_{F}$

If $\left(w_{i}=0\right)$

f. Determine $P_{i}$ : the set of pairings covering flight number $i$.

g. Choose pairing $q \in P_{i}$ randomly

h. Determine $F_{q}$ : the set of flight numbers covered by pairing $q \in P_{i}$

i. Update $S_{i} \leftarrow S_{i} \cup q, w_{i} \leftarrow w_{i}+1$ for $i \in F_{q}$

j. Update $U \leftarrow U-F_{q}, x_{q}=1$

End

End 


\section{RESULTS}

Data used in this research are obtained from one of Boeing 738 flight schedule in flight company in Indonesia. From Boeing 738 flight schedule, there are 214 flight numbers. First, we generate a set of possible pairings of each flight number. The results are as follows :

$\begin{array}{ll}\text { Pairing } A^{2} & : 337 \text { pairings } \\ \text { Pairing } A^{3} & : 44 \text { pairings } \\ \text { Pairing } A^{4} & : 3549 \text { pairings } \\ \text { Pairing } A^{5} & : 91 \text { pairings } \\ \text { Pairing } A^{6} & : 1269 \text { pairings }\end{array}$

After the set of possible pairings are generated, they will be selected a set of selected pairings subject to all flight number are covered by one pairing. When the set of selected pairing does not satisfy the constraint in equation (2), then it occurs deadhead and penalty cost will be given.

Cost of pairing is constructed as follows :

$\begin{array}{ll}\text { Cost of Pairing } A^{2} & : 5 \\ \text { Cost of Pairing } A^{3} & : 4 \\ \text { Cost of Pairing } A^{4} & : 3 \\ \text { Cost of Pairing } A^{5} & : 2 \\ \text { Cost of Pairing } A^{6} & : 1 \\ \text { Cost of deadhead } & : 10\end{array}$

In Boeing 738 airline, pairing with higher $n$ flight numbers has lower cost and vice versa because pairing with higher $n$ flight numbers can cover all flight number by fewer total pairings so that the number of crew employed is fewer. Deadhead is the case in which there are same flight numbers in the different pairing so that the flight number is covered more than one pairing. This problem causes a set of crews is transfered to destination airport with other flight in different pairing. In the optimal pairing selection, deadhead is penalty so that cost of deadhead is higher than cost of pairing.

Figure 7 shows the simulation of GA on optimal pairings selection optimization. In early time, the chromosomes are chosen randomly. In the optimization process, the chromosomes are updated by selection, crossover, and mutation so that fitness will decrease and converge. In updating chromosomes, in order that satisfying constraints, chromosome will be given penalty if the constraint isn't satisfied.

From the GA simulation with the number of population is 10 , crossover probability is 0.5 , mutation probability is 0.5 . and maximum iteration is 50 , the objective value as fitness is 1050. The cost of pairings as main objective function is 190 and cost of deadhead as penalty is 860 . The number of pairings selected are :

$\begin{array}{ll}\text { Pairing } A^{2} & : 1 \text { pairings of } 337 \text { pairings } \\ \text { Pairing } A^{3} & : \text { a pairings of } 44 \text { pairings } \\ \text { Pairing } A^{4} & : 51 \text { pairings of } 3549 \text { pairings } \\ \text { Pairing } A^{5} & : 5 \text { pairings of } 91 \text { pairings } \\ \text { Pairing } A^{6} & : 10 \text { pairings of } 1269 \text { pairings } \\ \text { Deadhead } & : 86 \text { flight numbers }\end{array}$




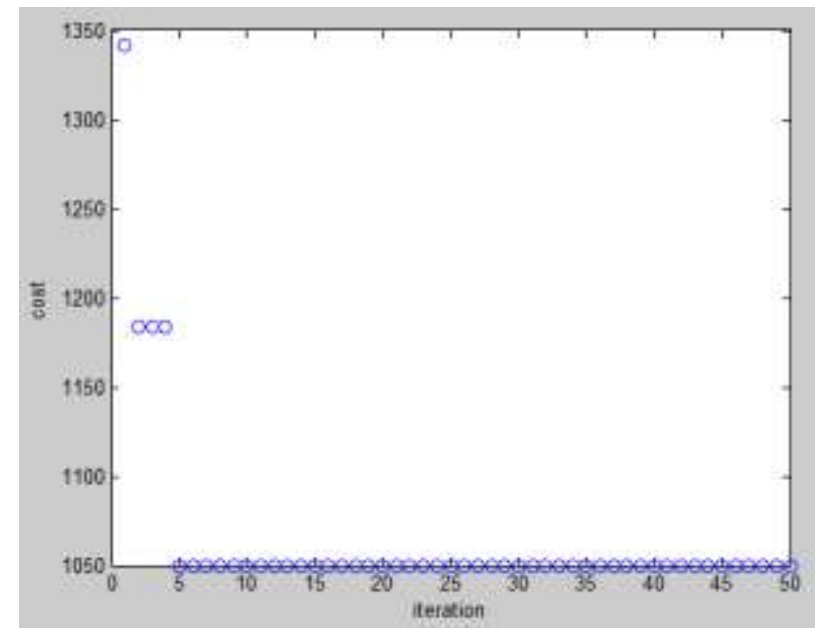

Fig. 7 GA Optimization Process

Figure 8 shows the simulation of PSO on optimal pairings selection optimization. In early time, the particle positions are chosen randomly. In the optimization process, position and velocity particle are updated so that fitness will decrease and converge. In updating particle position, in order that satisfying constraints, particle will be given penalty if the constraint isn't satisfied.

From the PSO simulation with the number of population is 10 and maximum iteration is 50 , the objective value as fitness is 944 . The cost of pairings as main objective function is 194 and cost of deadhead as penalty is 750 . The number of pairings selected are :

Pairing $A^{2} \quad: 3$ pairings of 337 pairings

Pairing $A^{3} \quad: 4$ pairings of 44 pairings

Pairing $A^{4} \quad: 50$ pairings of 3549 pairings

Pairing $A^{5} \quad: 1$ pairings of 91 pairings

Pairing $A^{6} \quad: 11$ pairings of 1269 pairings

Deadhead : 75 flight numbers

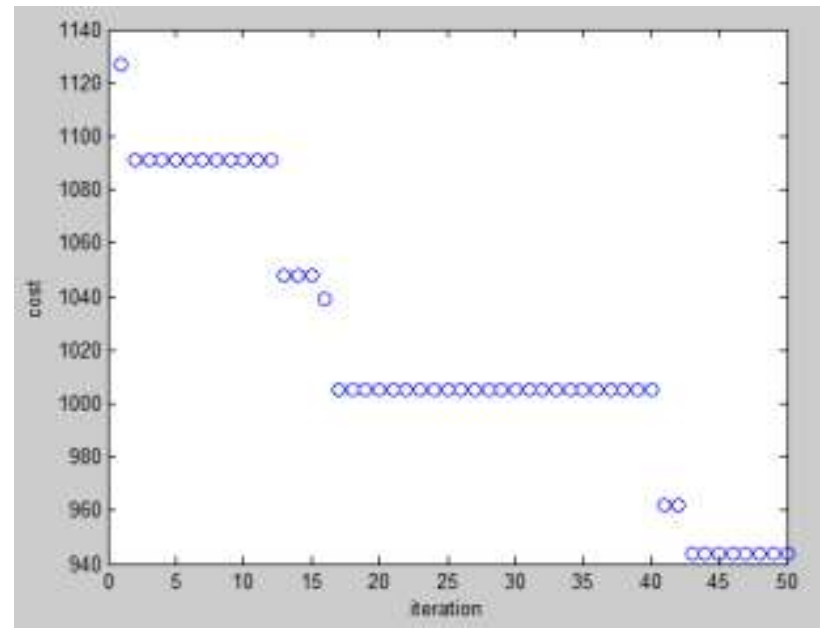

Fig. 8 PSO Optimization Process

\section{CONCLUSION}

Optimal pairings selection is one of constrained optimization with decision variable is binary. The constraints are all flight numbers should be covered by one pairing. 
Simulations are applied by generating the set of possible pairings. After the set of possible pairings are generated, then we select the set of selected pairings using GA and PSO with penalty if the flight number is covered more than one pairing. Modified crossover and mutation in GA or particle position and velocity in PSO are required because the decision variable is binary. Simulation result shows GA and PSO method with penalty can select optimal pairings in approaching. The developments from these results are assinging the set of crew for operating the pairings.

\section{REFERENCES}

[1] Bansai J C and Deep K 2012 A Modified Binary Particle Swarm Optimization for Knapsack Problems Applied Mathematics and Computation 218 pp. 11042-11061.

[2] Gen M and Cheng R 1997 Genetic Algorithm and Engineering Design (New York : John Wiley and Sons)

[3] Griva I, Nash S G and Sofer A 2009 Linear and Nonlinear Optimization (Philadelpia : Society for Industrial and Applied Mathematics)

[4] Herlambang T, Rahmalia D, Yulianto T 2019 Particle Swarm Optimization (PSO) and Ant Colony Optimization (ACO) for Optimizing PID Parameters on Autonomous Underwater Vehicle (AUV) Control System Journal of Physics : Conference Series vol.1211 (Jember : Universitas Negeri Jember)

[5] Hillier F S and Lieberman G J 2001 Introduction to Operations Research (New York : Mc Graw Hill)

[6] Kennedy J and Eberhart R C 1995 Particle Swarm Optimization Proceedings IEEE Int. Conf. Neural Network pp. 1942-1948.

[7] Rahmalia D 2017 Particle Swarm Optimization-Genetic Algorithm (PSOGA) on Linear Transportation Problem International Conference on Mathematics : Pure, Applied and Computation-2016 AIP Conference Proceedings vol. 1867 pp. (020030)1-12 (Surabaya : Institut Teknologi Sepuluh Nopember)

[8] Rahmalia D, Novianingsih K and Hadianti R 2013 Optimisasi Crew Pairing dengan Momodifikasi Jadwal Penerbangan Tesis Magister Matematika ITB

[9] Rao S S 2009 Engineering Optimization Theory and Practice (New Jersey : John Wiley and Sons)

[10] Muhith A., and Herlambang, T. 2019. "Estimation of Availability of Whole Blood (WB) at PMI Surabaya City Using Kalman Filter as Management of Blood Bank", The $1^{\text {ST }}$ International Conference On Bussines, Law, And Pedagogy, 13-14 February 2019

[11] Muhith A., and Herlambang, T. 2019. "Estimation of Packed Red Cells (PRC) Blood Stock Using Extended Kalman Filter as Management of Blood Transfusion at Blood Bank of PMI Surabaya", The $1^{\text {ST }}$ International Conference On Bussines, Law, And Pedagogy, 13-14 February 2019

[12] Muhith A., Herlambang, T., Zuhdi, U., and Rahmalia, D. 2019. "Estimation of Availability of Whole Blood (WB) and Washed Erythrocyte (WE) Using Ensemble Kalman Filter as Blood Transfusion Management in PMI Surabaya", Seminar International Health Conference, 13-14 July 2019

[13] Muhith A., Herlambang, T., Haris, A., and Rizqina, R. 2019. "Estimation of Whole Blood (WB) using Unscented Kalman Filter for Blood Bank Management", The International Conference On Bussines and Management of Technology, 3 August 2019. 
International Journal of Advanced Science and Technology Vol.134 (2020) 